\section{THE LATE INQUEST AT PUTNEY.}

\section{To the Editor of The LaNoET.}

Sir,-As the person directly implicated by your remarks in the last number of THE LAXCET, in reference to the unfortunate event recently the subject of inquiry at Putney, I feel called upon to trouble you with the following remarks, trusting to your sense of justice for their insertion; for I cannot persuade myself you can, after so personal an attack, refuse the reasonable request I make, to be allowed to defend myself through the same channel. In entering upon this detail, I am perfectly well assured that I expose myself to further censure at your hands if I mis-state even the most unimportant facts; but inasmuch as I am borne out by the family of the deceased, as well as by the medical gentlemen who gave their testimony at the inquest, I have no hesitation in asserting, plainly and distinctly, that the statements in THE LAFCET, which serve as a basis to your editorial article, are at variance with the truth in very many important particulars; and the report, as a whole, garbled, incomplete, and partial.

The facts, even if correctly stated, would, in my humble opinion, apply as well to Dr. Cormack as myself. That gentleman, though a physician, is the proprietor of a druggist's shop, as like my own in appearance and objects as is possible to render it; he would be a bold man to deny this; and I will venture to assert, had any one gone to that shop before this melancholy occurrence, and asked the assistant to supply medicine for a person labouring under a supposed bilious attack, that drugs of a similar description to those supplied by me to the deceased, Miss Dallett, would have been handed over the counter with as little hesitation, and perhaps in exchange for as few pence. Will Dr. Cormack, then, or any one else, be good enough to point out to me why a mild mercurial, and an equally mild aperient, coming from one shop, should be set down as "rank poisons," and as "razors placed in the hands of suicides;" whilst out of another shop, two or three hundred yards distant, the same drugs should be deemed efficient and proper remedies for disease? I shall be told, perhaps, that the medicines in the one case being dispensed by a mere pharmaceutist, and in the other by a person who had the distinguished privilege of mixing salts and senna together before 1815, makes all the difference. It may be so, but common sense refuses to mark this distinction; but even without having recourse to an hypothesis, it may be remarked that there is still in the possession of Mr. Dallett an aperient mixture, prescribed and sent by Dr. Cormack, to be taken by the unfortunate deceased on the very morning which closed her existence. If, then, medicines of this description, at the outset of a malady, when merely functional disturbance is suspected, surely the intended exhibition of a similar medicine, at a time when organic lesion ought to have been evident to a "gentleman having an adequate knowledge of his profession," must be open to strictures of a much severer character. But admitting that druggists act illegally in administering to the relief of the most simple ailments, admitting, too, if you will, that, as a druggist, I have no right to supply even a black draught to an individual applying for the same, is it fair, is it honest, to place the whole onus of such a case as that of Miss Dallett-the mistake about the narcotism-the misdirection of the pills, \&c.- upon my shoulders?

I may know but little of the practice of medicine, (as a druggist;) you seem to think I cannot possess capacity enough to embrace even the first rudiments of the science, but I flatter myself I may know sufficient to form a judgment, in common with the public, upon the possible result of a different mode of treatment, had it been pursued, in the unfortunate case that has given rise to so much discussion; that is to say, had the patient been treated, during her latter hours, for the prostration and collapse consequent upon fever, instead of being hurried from room to room, slapped, pinched, \&c., under the impression that the poor young girl was labouring under narcotism, by the doctor's own confession, and, as he said, arising from his own remedies.

Again, Sir, permit me to ask, Is the sworn testimony of the medical witnesses, in reference to the medicines furnished by me to Miss Dallett, to go for nothing? What says Dr. Cormack himself? "I did not convey, nor do I wish to convey, the impression that the disease arose from improper medicines furnished by Mr. Farmer." If this alone does not acquit me of all blame in the transaction, $T$ have still the testimony of Dr. Wane in my favour: although the following important part of Dr. Wane's evidence has been suppressed in the reports of the inquest in the public papers, I am fortunate in having it in my power to give the substance of it, (from the notes of a gentleman present at the inquiry, kindly furnished me " Does not think the medicines furnished by Mr. Farmer were of that nature to produce any of the appearances he had described. Does not consider them dangerous medicines, 0 medicines that were in any way hurtful to the deceased; and certainly were not such as were calculated to hasten the result." Now, in the face of such evidence as this, and bearing in mind that no imputation was cast upon me, eithe in the charge of the Coroner, or in the verdict of the jury among whom were a medical man and a barrister, $I$ think have a right to ask, on what grounds I am directly charged with a crime little short of homicide, in fact, with the death of a young lady, for whom, on being applied to, I furnished a mild mercurial and a black draught, medicines which person in every station of life are in the daily habit of procuring from chemists, upon their own responsibility, albeit, they may be within reach of multitudes of medical men of first. rate talents.-I am, Sir, your most obedient servant,

Putney, July, 1847. John Farmer.

* We have thought it right to insert the foregoing letter from Mr. Farmer. Of course it does not alter our opinion of the impropriety and danger of druggist-practice. Our remarks applied to the system of suggesting or ordering medicine over the counter for patients labouring under dangerous or fatal diseases, or indeed at all.-ED. L.

\section{LIFE ASSURANCE-FEES TO MEDICAL MEN.}

To the Editor of THE LanceT.

Sin,-As the question of "Life-Assurance Offices versus Medical Men" is once more revived, I think it right to state that for the last ten years I have invariably returned the list of "confidential questions" to the Secretary, unanswered merely saying that when the usual fee of one guinea is forwarded, I should be happy to give my best attention to the matter, as I am perfectly convinced the assurance offices are the parties most benefited by the information.

In about two cases in each year I have had fees remitted to me, and in one case very lately, (where the life was refused, I received the thanks of the directors for the facts rendered to them, which they could not possibly have obtained through their appointed medical officer.

It appears to me that the standing appointments of surgeons and physicians to life offices are great pieces of humbug, and were probably created, originally, by the directors, for some of their young friends. That they have no confidence in them is very clear, and in my opinion, very properly so, as I am convinced that in many instances they may be very readil imposed upon by applicants who, when about to insure their lives, will live very moderately for a time, in order (as they have often told $\mathrm{me}$ ) to put themselves in trim for the "over hauling" of the said standing medical officers. In conclusion. I would advise my professional brethren to invariably refuse the required answers, except to those offices who pay medical men for the services they require, and to make a point of rejecting the fee from their patients, at the same time explaining to them our views upon the subject.

I am, Sir, your obedient servant

Spital-square, July, 1847.

$$
\text { JoszpH Hodgson, M.R.C.S.E., L.A.C. }
$$

\section{ON THE PHYSIOLOGY OF THE UTERUS.}

\section{To the Editor of THe LavoeT.}

SiR,-At the present time, there is no subject of deeper interest to the physiologist, pathologist, and practical accoucheur, than the anatomy of the unimpregnated and gravid uterus. Without a correct knowledge of the anatomica structure of the uterus, it is obvious that all our reasonings respecting the functions and diseases of the organ must be hypothetical, and without any solid foundation. All its struc tures, cellular, vascular, and muscular, appear to be positively ascertained by dissection. About these there is no difference of opinion, and all admit that they enlarge during pregnancy but about the nervous structures of the uterus there still exists great diversity of opinion, and some maintain that the nerves undergo no change during pregnancy. From the functions and diseases of the uterus, it might, a priori, have been inferred that the uterus does possess a great and peculiar system of nerves, and that these must grow with the other structures after conception. Great structures, accompanied by bloodvessels, and having all the character of nervous ganglionic plexuses, have been demonstrated to exist at the 